\title{
The Impact of Delaying Retirement on Chinese Employment and Economic Growth under the Background of Aging
}

\author{
Haiyang Zhang ${ }^{1}$ \\ ${ }^{1}$ School of Management, Shanghai University of Engineering Science, China \\ Correspondence: Haiyang Zhang, School of Management, Shanghai University of Engineering Science, Shanghai, \\ China. E-mail: mike1xiwo@163.com
}

Received: August 15, 2014

Accepted: August 25, 2014

Online Published: September 1, 2014

doi:10.5430/jbar.v3n2p54

URL: http://dx.doi.org/10.5430/jbar.v3n2p54

\begin{abstract}
In accordance with international standards for the aging society division, China has entered the aging society since 2000, and the aging degree is deepened ceaselessly. To actively deal with adverse effects on labor market and economic development which brought by the aging of the population, it is imperative for Chinese government to reform the retirement system. This paper uses employment substitution effect and the employment elastic coefficient to analyze the effects on economic growth and employment of delaying retirement, and predict reasonable retirement age. As a result, through theoretical analysis, delaying retirement won't cause large scale unemployment, as well as new retirement age should not be over the age of 65 , to promote the role of economic growth, otherwise it will stifle economic growth.
\end{abstract}

Keywords: Population aging, Retirement age, Employment, Economic growth

\section{Introduction}

China has entered the aging society since 2000, the aging degree is deepened ceaselessly. It is generally believed that the aging of the population will cause the reduction of the workforce, increase pension pressure, and affect the development of the economy. In order to reduce the adverse effect of aging on Chinese employment and economic development, delaying retirement is generally considered a countermeasure. It is not only the objective laws, but also meets the necessary means of social old-age security. Through an analysis of employment substitution effect theory, to study the relationship between delaying retirement and the labor supply, employment elasticity coefficient to predict reasonable retirement age at the same time, aiming to provide Chinese government some recommendations for reference to reform the retirement system.

\section{The Necessity to Delay Retirement}

\subsection{Delaying Retirement is the Objective Law}

The policy of retirement should not be fixed. The objective trend of the economic, social, and demographic development all have forced the retirement age adjusted. Both in the developed and developing countries, the statutory retirement age starts to be postponed. It seems to become a global trend, as the table 1 shows (Shao Guodong, Zhu Xiaoyu \& Liu Wei, 2007). At present, the retirement policy arrangement in China is that, male workers aged over 60 years old, who have served for 25 years; female workers over 50 (female cadres, 55 years old), who have served for 20 years, then they can retire. Meanwhile, the sixth Chinese census data (2010) shows that: the average life expectancy of the Chinese population is 78.61 years old; the average male life expectancy is 76.16 years, female 81.06 years old. Due to improved medical care, health and living standards, the average life expectancy of the population increases nearly 20 years compared to it in the $1950 \mathrm{~s}$, but Chinese retirement system still use the old standards, which is obviously ignore the objective law changes. 
Table 1. Some countries postponed or delayed retirement age scheme

\begin{tabular}{lccc}
\hline Country & $\begin{array}{c}\text { The statutory } \\
\text { retirement age in } \\
\text { 2002(years old) }\end{array}$ & $\begin{array}{c}\text { The objective retirement } \\
\text { age(years old) }\end{array}$ & $\begin{array}{c}\text { The time to reach } \\
\text { the target retirement } \\
\text { age(year) }\end{array}$ \\
\hline America & 65 & 67 & 2027 \\
Britain & $65(\mathrm{M}), 60(\mathrm{~F})$ & 68 & $2024-2046$ \\
Germany & 65 & 68 & 2029 \\
Italy & $62(\mathrm{M}), 57(\mathrm{~F})$ & 65 & 2018 \\
Japan & 60 & 65 & M:2025, F:2030
\end{tabular}

Data source: Shao Guodong, Zhu Xiaoyu \& Liu Wei (2007). The study on the reasonableness of delaying retirement based on the life-cycle theory. Social Sciences in Yunnan, No, 5: 53-56, 88.

\subsection{Delaying retirement is the need of social endowment insurance}

During the transform from the PAYG system to partially funded system, a huge gap of pension emerged in Chinese endowment insurance system (Zhu Xiaotao, 2013). The human resources and social security undertakings development statistics bulletin (2008) shows that from 2006 to 2008, Chinese pension costs rose to 739 billion RMB from 489.7 billion RMB, an average annual increase of $22.84 \%$. According to the prediction of World Bank, from 2001 to 2075, the revenue and expenditure gap of the basic old-age insurance will reach 915 million RMB in China, which will bring huge pressure to national finance.

At the same time, due to the urban-rural dual economic structure of society, the coverage of the Chinese social security system which established in the 1980s is still narrow, and far from covering all rural areas with all types of social security benefits (Peng Xizhe \& Hu Zhan, 2011). In this context, to delay retirement can alleviate social pressures of pension to some extent.

\section{The Impact of Delaying Retirement on Employment and Economic Growth}

\subsection{The Impact of Delaying Retirement on Employment}

Under the condition that the number of jobs provided by society is limited, especially in severe cases of population aging, extending the retirement age could relieve the approaching workforce reduction situation. However, the retirement age will be extended at the cost of decreasing other people's opportunities in the work field, which would bring a substitution effect of employment (Xu Wenquan, Liang Dong \& Yue Haoyong, 2006).

The substitution effect of employment size should be divided into two kinds of situations to discuss:

Firstly, when under the planned economy system, jobs would be arranged by the government, and the chance of reappointing the retired would be little. Therefore, extending the retirement age will reduce the replacement of old and new labor force, squeeze jobs for young people, and produce a larger substitution effect of employment.

Secondly, when under the market economy system, there are a lot of retirees would be rehired. Even though some people choose to retire early, there won't be more jobs provided. At this case, the substitution effect of employment which brought by extending the retirement age will be smaller.

Along with the growth of the age, the retired will lose some energy in work field, compared with young people full of vitality. But a wealth of experience could make them have more advantages in certain positions than young people, so the rehiring phenomenon appeared. On the contrary, extending the retirement age promotes employment. For that reason, many countries regard retirees' employment as the way to increase social wealth, and they encourage it instead of exclusion.

In summary, the results from the theoretical analysis shows that the substitution effect of employment caused by extending retirement is smaller under the market economy system, and delaying retirement could promote employment. According to the net employment effect of delaying retirement (employment promotion effect employment substitution effect), delaying retirement could not cause a high unemployment rate. 


\subsection{The Impact of Delaying Retirement on Economic Growth}

\subsubsection{Research Method}

According to the labor economic, employment elasticity coefficient is a most commonly used indicator to measure the relationship between economic growth and employment growth (Chi Biyun, 2006 \& Cheng Liansheng, 2007). Therefore, the paper uses it to analyze the impacts of delaying retirement on Chinese economic growth. The relationship between economic growth rate $P$ and employment growth rate $Q$ can be expressed as:

$$
Q=\beta \cdot P
$$

Among them, $\beta$ indicates the employment elasticity coefficient, i.e. as GDP growth by one percentage point, it can drive the percentage points of employment. The larger $\beta$ is, the stronger the ability to attract labor force, and vice versa .Under certain conditions, the larger $\beta$ is, the higher $Q$ is. Employment growth rate $Q$ is the ratios between employment increased volume and the amount of the initial employment. $L_{0}$ indicates the number of labor force to participate in employment, $\Delta L$ is the increasing amount of employment. Thus the rate of employment growth $Q$ can be expressed as:

$$
Q=\frac{\Delta L}{L_{0}}
$$

Put (1) into (2):

$$
P=\frac{\Delta L}{L_{o} \beta}
$$

To analyze the impact of delaying retirement on Chinese economic development, is to study the effect of increased employment on the Chinese GDP growth rate due to delaying retirement, so (3) is limited to the relationship between the workforce and the economic development under the conditions of delaying the retirement age.

$$
P=\frac{\Delta L^{\prime}}{L^{\prime} \beta}
$$

$L^{\prime}$ refers to the employment in the case of the retirement age not changed, $\Delta L^{\prime}$ refers to the labor force increment as a result of delaying the retirement age, which equals to the actual number of employees under delaying retirement age subtracting the actual number of employees without postponing retirement age.

It is necessary to explain that there is a huge number of employment statistics, with many uncertainty factors, so the paper uses the statistics of the number of people of all ages $L_{i}$ and the age of the labor force participation rate $\gamma_{i}$ to reflect changes in employment, $L, \gamma$, refers to the age of employment.

When the workers work from $a$ years old to retire at $b$ years old, then all the employment number can be expressed as $\sum_{i=a}^{b} L_{i} \gamma_{i}$, if delay the retirement age from $b$ years old to $b+k$ years old, the number of social employment will become $\sum_{i=a}^{b+k} L_{i} \gamma_{i}$ after the policy change, and the incremental number of labor will be $\Delta L=\sum_{i=a}^{b+k} L_{i} \gamma_{i}-\sum_{i=a}^{b} L_{i} \gamma_{i}$, which means the growth rate of GDP.

$$
P=\left(\sum_{i=a}^{b+k} L_{i} \gamma_{i}-\sum_{i=a}^{b} L_{i} \gamma_{i}\right) / \beta \sum_{i=a}^{b} L_{i} \gamma_{i}
$$

Because the labor participation rate between male and female is different and the difference is bigger, it should be considered separately. Therefore the paper improves the model, making it more realistic. Male people with $i$ years old is expressed by $L_{1 i}$, the labor force participation rate is expressed by $\gamma_{1 i}$, so the same with women $L_{2 i}, \gamma_{2 i}$. So considering the case of men and women, the model is:

$$
P=\left(\sum_{i=a}^{b+k}\left(L_{1 i} \gamma_{1 i}+L_{2 i} \gamma_{2 i}\right)-\sum_{i=a}^{b}\left(L_{1 i} \gamma_{2 i}+L_{2 i} \gamma_{2 i}\right)\right) / \beta \sum_{i=a}^{b}\left(L_{1 i} \gamma_{1 i}+L_{2 i} \gamma_{2 i}\right)
$$

\subsubsection{Research Content}

Based on the statistical data of 2010, the paper finds out the national men and women of all ages population and labor force participation rate, as the table 2 shows. 
Table 2. 2010 National men and women of all ages and labor force participation rate

\begin{tabular}{llccc}
\hline Age group & Male population & $\begin{array}{c}\text { Male labor force } \\
\text { participation rate(\%) }\end{array}$ & $\begin{array}{c}\text { Female } \\
\text { population }\end{array}$ & $\begin{array}{c}\text { Female labor force } \\
\text { participation rate(\%) }\end{array}$ \\
\hline $15-19$ & 51904830 & 25.5 & 47984284 & 30.4 \\
$20-24$ & 64008573 & 81.7 & 63403945 & 72.2 \\
$25-29$ & 50837038 & 96.4 & 50176814 & 82 \\
$30-34$ & 49521822 & 96.9 & 47616381 & 84.1 \\
$35-39$ & 60391104 & 96.7 & 57634855 & 85.7 \\
$40-40$ & 63608678 & 95.8 & 61145286 & 84.6 \\
$45-49$ & 53776418 & 93.8 & 51818135 & 76.4 \\
$50-54$ & 40363234 & 88.6 & 38389937 & 63.9 \\
$55-59$ & 41082938 & 75.6 & 40229536 & 52.1 \\
$60-69$ & 50582897 & 25.5 & 49197667 & 15.2 \\
\hline
\end{tabular}

Data source: 2010 national population by gender and age. http://www.luqyu.cn/html/4/2012/content-390.html

According to the statistics of the State Statistical Committee, the employment elasticity is our basic in the range of 0.01-0.15.The paper selects 0.013 as the employment elasticity coefficient based on the changes in the employment elasticity in recent years. According to this situation that the labor force participation rate is lower and the number of employment in each age after 60 years old tends to decline, it is assumed that the labor force participation rate remains unchanged, and the number of employment is in the form of descending arithmetic sequence. The paper chooses 10116578 as the first series of male population after 60 years old, with 1124063 as the tolerance of the arithmetic sequence, and 10806510 as the first series of female population, with 1204391 as the tolerance, then calculates the rate of increment of labor force after delaying $k$ years, and chooses $k$ as the independent variables, along with the increment of GDP as the dependent variable. In addition, the paper uses MATLAB to get the image of GDP growth rate with extending the retirement age, as the figure 1 shows.

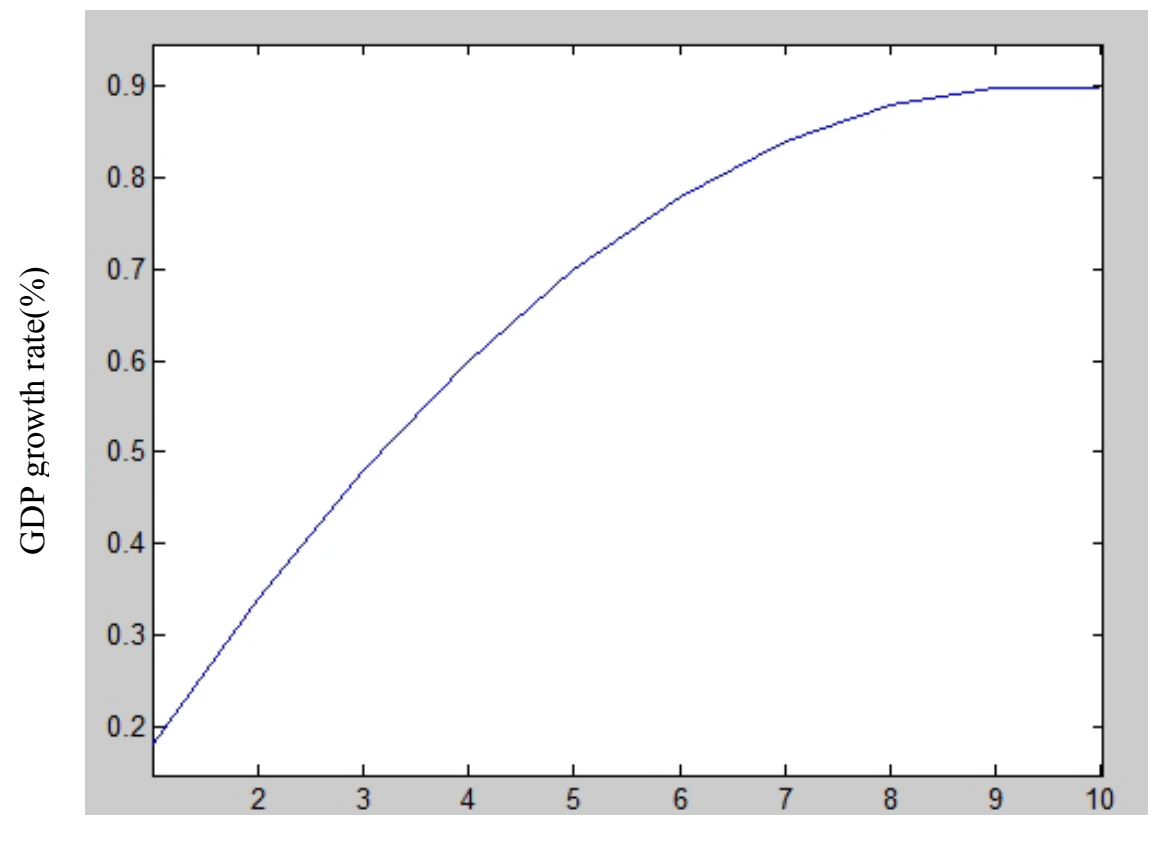

The year of delaying retirement

Figure 1. The image of GDP growth rate with extending the retirement age 


\subsubsection{Research Result}

Figure 1 shows that, the GDP growth rate is on the increase with the extension of the retirement age. But when $\mathrm{k} \leq 5$, the GDP growth rate increases with extending the retirement age. While $\mathrm{k}>5$, the speed of growth slows down, and delaying retirement is likely to squeeze the position supply, and then exacerbates the tensions of the youth employment situation. So the paper draws this conclusion: the time of extending the retirement is not more than 5 years, which means not more than 65 years old.

Put $b=60, k=5, \beta=0.25$ into the model:

$$
P=\left(\sum_{i=a}^{b+k}\left(L_{1 i} \gamma_{1 i}+L_{2 i} \gamma_{2 i}\right)-\sum_{i=a}^{b}\left(L_{1 i} \gamma_{2 i}+L_{2 i} \gamma_{2 i}\right)\right) / \beta \sum_{i=a}^{b}\left(L_{1 i} \gamma_{1 i}+L_{2 i} \gamma_{2 i}\right)
$$

Then get $P=0.7 \%$, that is to say, when the government adjusts the retirement age to 65 years old, the GDP growth rate is $0.7 \%$.

\section{Discussion}

From the discussion and analysis, delaying retirement won't cause a high unemployment rate and the appropriate retirement age is not over 65 years old that can contribute to the economic growth. From those, it is an inevitable trend in China .Therefore, the paper suggests Chinese government take the gradual approach to delay it with the help of doing positive advocacy, in order to eliminate some people's resentment, and make people gradually accept the implementation of this policy. At the same time, the government should also make some appropriate corresponding measures of reform. For example, according to the actual retirement age the pension replacement rate can be divided into different grades, that is to say, the later retirement age, the higher pension level.

It should be noted that, the paper bases on $Q=\beta \cdot P$ and uses the labor participation rate to calculate the labor population, then puts it into MATLAB software to make the image. However, due to the lack of per number of age 60-69 and their labor participation rate, the paper assumes that the number of population after 60 years old is decreasing in the form of arithmetic sequence, and the labor force participation rate remains unchanged. There is a deviation from the actual circumstances which leads to have a prediction error. The author will do some further research on the basis of this paper to find out the necessary policies which are needed to carry on the corresponding reform, and how to reform and other issues.

\section{References}

Cheng Liansheng. (2007). An Attribution Study of the Changing Tendency of Rapid Economic Growth Accompanied by a Low Employment Rate in China. Teaching and research, No.3: 35-41.

Chi Biyun. (2006). The study of Chinese employment growth on the view of the employment elasticity. Statistical Education, No.4: 50-51.

Peng Xizhe \& Hu Zhan. (2011). Chinese population aging under the perspective of public policy. Social Sciences in China, No.3: 121-138.

Shao Guodong, Zhu Xiaoyu \& Liu Wei. (2007). The study on the reasonableness of delaying retirement based on the life-cycle theory. Social Sciences in Yunnan, No.5: 53-56, 88.

Xu Wenquan, Liang Dong \& Yue Haoyong. (2006). Adopt the reform of flexible retiring age to reduce the pension gap: based on the human capital theory. MARKET \& DEMOGRAPHIC ANALYSIS, V.12No.2: 33-37.

Zhu Xiaotao. (2013). Discussion of Chinese pension stealth debt problems. Laodong Baozhang Shijie, No.4: 16-18. 